\title{
A DESJUDICIALIZAÇÃO COMO ALTERNATIVA À CRISE DA JURISDIÇÃO NA ÁREA DA SAÚDE
}

\author{
José Laurindo de Souza Netto \\ Autor correspondente. Universidade Paranaense - Mestrado em Direito Processual e Cidadania - Campus Sede. \\ Praça Mascarenhas de Moraes, s/no, Centro. Umuarama/PR, Brasil. CEP 82410-730. http://lattes.cnpq.br/8509259358093260. \\ https://orcid.org/0000-0002-6950-6128. jln@tjpr.jus.br \\ Anderson Ricardo Fogaça \\ Tribunal de Justiça do Estado do Paraná. Curitiba/PR, Brasil. http://lattes.cnpq.br/93436567858887913. \\ https://orcid.org/0000-0001-8495-9443. arf@tjpr.jus.br \\ Adriane Garcel \\ Tribunal de Justiça do Estado do Paraná. Curitiba/PR, Brasil. http://lattes.cnpq.br/3684019694966209. \\ https://orcid.org/0000-0002-5096-9982. adriane.garcel@tjpr.jus.br
}

O presente artigo tem por objetivo abordar o acesso à Justiça, debruçando-se, especialmente, sobre como o número exacerbado de demandas individuais envolvendo o direito à saúde afeta a efetividade e celeridade do trâmite de ações no poder Judiciário, mostrando-se urgente o fomento de meios pré-processuais de resolução de conflitos para se obter um desempenho melhor na solução de litígios para a sociedade. Nesse contexto, procura-se repensar essa sistemática partindo de mecanismos extraprocessuais e pré-processuais de solução de conflitos. Far-se-á uma abordagem do acesso à Justiça não só como garantia de acesso ao poder Judiciário e a um julgamento justo, mas com base na premissa de que o acesso à Justiça está garantido pelos meios pré-processuais de resolução de conflitos quando houver a participação, em alguma medida, do poder Judiciário, seja como participante ativo do sistema pré-processual ou mero fomentador. Nessa medida, fala-se em Métodos Socialmente Adequados de Resolução de Conflitos.

Palavras-chave: desjudicialização; acesso à Justiça; métodos socialmente adequados de resolução de conflitos; poder Judiciário.

\section{JUDICIALIZATION AS AN ALTERNATIVE TO THE CRISIS OF HEALTH JURISDICTION}

\section{ABSTRACT}

This article aims to address access to justice, focusing in particular on how the exacerbated number of individual demands involving the right to health affect the effectiveness and speed of the course of action in the judiciary. pre-procedural means of conflict resolution for better performance in resolving disputes for society. In this context, we seek to rethink this system based on non-judicial mechanisms for conflict resolution. Access to justice will be approached not only as a guarantee of access to the judiciary and fair trial, but on the premise that access to justice is guaranteed by pre-procedural means of conflict resolution when the participation, to some extent, of the judiciary, either as an active participant in the pre-procedural system or as a mere sponsor. To this extent, we talk about Socially Appropriate Methods of Conflict Resolution.

Keywords: dejudicialization; access to justice; socially appropriate methods of conflict resolution; Judicial power.

Recebido em: 6/11/2019

Aceito em: 31/5/2021 


\section{INTRODUÇÃO}

O presente artigo tem por objetivo abordar o acesso à Justiça, debruçando-se, especialmente, sobre como o número exacerbado de demandas individuais envolvendo o direito à saúde afetam o poder Judiciário, mostrando-se urgente o fomento da desjudicialização para se obter um efetivo e mais célere desempenho na solução de litígios para a sociedade.

Conforme dados do Conselho Nacional de Justiça, é notório que o acesso à Justiça vem sendo utilizado de maneira predatória: os jurisdicionados enxergam a ação judicial como a porta de entrada para a resolução de seus problemas, e não como última ratio. Um sistema de Justiça sustentável, porém, reclama acessibilidade por todos e produção de resultados que sejam individual e socialmente justos.

$\mathrm{O}$ acesso à Justiça, todavia, pode ser discutido em três posições básicas. A primeira delas se distingue pela procura de assistência jurídica, atendendo necessariamente ao ingresso dos menos beneficiados ao sistema judiciário e à assistência de direitos individuais. A segunda seria qualificada para proporcionar o ingresso ao Judiciário de grupos identificados ou não com o desígnio de proporcionar assistência a direitos coletivos e difusos. Logo, a terceira posição procuraria um ponto de vista amplo, alinhado em relação a outros elementos na noção de acesso à Justiça e, além de incluir os avanços decorrentes dos posicionamentos anteriores, propõe-se a ir além e debater formas de acesso à Justiça de maneira mais ampla. Na linha dessa terceira posição permanecem a criação de órgãos especializados e a institucionalização de formas alternativas e adequadas ao sistema judiciário tradicional para a solução de conflitos (FELTEN, 2014, p. 30-41).

Cada processo em trâmite, no Brasil, tem um valor muito elevado. Se considerarmos que o poder Judiciário, em todas suas esferas de competência, segundo dados do Justiça em Números 2018, do CNJ (BRASIL, 2018), teve um total de despesa, em 2017, de cerca de 90,8 bilhões de reais, e que, naquele ano, havia cerca de 80,1 milhões de processos em trâmite, conclui-se que cada processo em trâmite custa, aproximadamente, $\mathrm{R} \$ 1.120,00$ (um mil, cento e vinte reais) por ano. Com o fim de reduzir o custo dessa transação, deve-se fazer uma releitura do direito de acesso à Justiça para além do acesso a uma ordem jurídica justa, efetiva e célere, mas para que o conflito seja resolvido pré-processualmente, com a chancela do poder Judiciário, tornando-se a fase pré-processual uma política judiciária em favor da desjudicialização, o que contribuirá ainda mais para a efetividade e celeridade do sistema de justiça.

Nosso sistema, no entanto, padece de uma crescente perda de funcionalidade. Conforme dados do CNJ, há cerca de 80,1 milhões de processos para cerca de 16.500 magistrados, com uma taxa de congestionamento de aproximadamente $74 \%$, o que significa dizer que, de algum modo, nesses 30 anos decorridos desde a promulgação da Constituição Federal de 1988, ampliou-se inegavelmente o acesso à Justiça, mas há um longo caminho para que se possa alcançar um equilíbrio entre qualidade e quantidade, entre celeridade e efetividade da jurisdição. A Justiça Comum Estadual é o segmento com maior representatividade de litígios no poder Judiciário, acumulando 69,4\% da demanda (BRASIL, 2018).

A melhor forma de desafogar o poder Judiciário é, em primeiro plano, prevenir o conflito, o que, em se tratando de demandas relativas à saúde, passa, necessariamente, pela rediscussão do contencioso administrativo prévio. Em segundo lugar, é preciso fomentar a cultura da tutela coletiva. 
No presente artigo busca-se analisar algumas questões necessárias ao fortalecimento do contencioso administrativo prévio ao ajuizamento de demandas relativas ao direito à saúde, apontando alternativas capazes de prevenir as lides. Ademais, pontuam-se aspectos relacionados a ações coletivas e de controle concentrado capazes de auxiliar no tratamento do problema.

Abordam-se, nesta perspectiva, os principais métodos socialmente adequados e alternativos para solução de conflitos, quais sejam: a expansão das Câmaras de Resolução de Litígios de Saúde (CRLS) e da mediação sanitária, os diálogos interinstitucionais como forma de facilitação da comunicação entre os envolvidos, o debate da política pública de saúde por meio de audiências públicas e a prioridade para as ações coletivas (ANDREUCCI, 2018).

\section{MÉTODOS SOCIALMENTE ADEQUADOS DE RESOLUÇÃO DE CONFLITOS}

Os Métodos Socialmente Adequados de Resolução de Conflitos representam a adesão à cultura da pacificação em oposição à da litigiosidade, com a solução pacífica mostrando-se sempre preferível, inclusive economicamente, o que não impede a busca vindoura pelo aparato judicial. Permanece uma atmosfera favorável para tais modelos, que também compõem instância legítima para a solução de conflitos sociais pelo adequado meio social, cogitando maior conscientização política e conhecimento popular.

Chegou-se a um momento da contemporaneidade em que a sociedade deve se emancipar para solucionar os seus próprios conflitos, com menos intervenção estatal, e o poder Judiciário deve contribuir para construir essa nova mentalidade no meio social. Por isso devemos falar em Métodos Socialmente Adequados de Resolução de Conflitos, e não mais em Métodos Alternativos de Resolução de Conflitos. Todos são alternativos à jurisdição propriamente dita, e, além disso, socialmente adequados, na medida em que visam à solução do conflito no seu nascedouro, antes da transformação do conflito de interesses em lide.

Essa percepção foi muito bem incorporada no Decreto no 8.243/2014, que regulamentou a Política Nacional de Participação Social e em que são mencionadas as Mesas de Diálogo. Delduque, Alves e Dallari (2015, p. 30) observam que "a Mesa de Diálogo representa um esforço em todos os níveis para gerar um efetivo acesso à Justiça, um novo mecanismo que pode ser considerado um esforço de mediação".

Nessa linha de raciocínio Toaldo e Berghahn (2014), com base no fundamento de Georges Gurvitch - o qual acredita que a evolução do Direito deve ser buscada na própria sociedade, e não na lei ou na jurisprudência - referem-se à concepção de um movimento pró-desjudicialização estabelecido por meio de uma alteração de condutas de analogias interpessoais que envolvem os profissionais de saúde, as instituições de serviços correlatos e os cidadãos/pacientes.

Com essa alteração de condutas, que fomenta uma inovação na maneira em abordar os litígios relacionados à área da saúde, surge a necessidade de priorizar a solução pacífica de controvérsias de maneira a atenuar a judicialização e dar outra perspectiva à realização do direito à saúde. É necessário pensar o acesso à Justiça também pela via da desjudicialização - e não mais apenas sob o clássico ponto de vista de Mauro Cappelletti - impondo-se uma mutação cultural na sociedade. Para isso, tende-se para os métodos consensuais de solução de litígios, por meio dos quais as partes do processo adotam para si o papel de protagonistas não somente da divergência, mas da adequada procura pela sua elucidação. 
Ronald Coase prevê que o cultivo de uma determinada atividade pode ser concretizado pela própria coordenação designada, ou de maneira descentralizada, por outros agentes econômicos. Quando descentralizada, o que incide em razão de custos altos em comparação com a dos outros, a atividade pode ser adimplida precisa e individualmente, por terceiros, por meio de negócios jurídicos (KLEIN, 2011, p. 71).

Pode-se dar como exemplo a conciliação, até pouco tempo atividade concretizada somente por magistrados. Os gastos envolvidos induziram um reparo para reconhecer sua efetivação por árbitros privados, selecionados pelas partes ou até mesmo por órgãos especializados, no caso as câmaras de conciliação privadas.

Krugman e Wells (2015, p. 11-16) ponderam que os espaços qualificados por maior liberdade das partes e menor intervenção do Estado frequentemente são mais competentes. No mesmo sentido, o Código de Processo Civil antevê de forma explícita a desjudicialização da atividade de mediação e conciliação, permitindo que os sujeitos escolham o mediador, o conciliador ou o órgão especializado nesta função.

Heitor Sica (2016, p. 435-460) menciona a "terceirização" para auxiliares da Justiça na efetivação de muitas das audiências preliminares do artigo 331 da legislação processual anterior, restringindo a aparição das atividades originariamente elencadas à conciliação.

O Código de Processo Civil de 2015 prevê de forma explícita a mediação como meio de solução de controvérsias entre particulares e sobre a autocomposição de conflitos no âmbito da administração pública. Não apenas foi regulamentado o instituto da mediação, como também anteviu a criação de câmaras de prevenção e resolução de conflitos, no âmbito da União, Estados, Distrito Federal e municípios.

Ainda a respeito da legislação oportuna ao tema, é digno de destaque a Resolução 125/2010, do CNJ, que constituiu a mediação e a conciliação como políticas públicas de tratamento de litígios, servindo como inspiração até mesmo para o Código de Processo Civil de 2015. Tem como objetivo essa Resolução garantir a toda população o direito à solução de seus litígios por meios pertinentes à sua natureza e peculiaridade. A Resolução também definiu que aos órgãos judiciários compete, além da solução alcançada por meio de sentença, apresentar outros métodos de solução de controvérsias, por meio de outros meios consensuais, como a mediação e a conciliação, bem como prestar atendimento e orientação à população (CARLINI, 2014).

Inclusive, no campo da jurisdição sanitária, a mediação revela-se como o método alternativo de resolução de conflitos mais adequado, pois, além de propiciar às partes a possibilidade de bem administrar seu próprio conflito, ela promove a inclusão e a participação sociais ${ }^{1}$ e valoriza a comunicação entre os litigantes.

Nesse diapasão, podemos observar que o Código de Processo Civil favoreceu as tentativas de solução pré-processual com o intuito de dar maior celeridade para resolver os conflitos, reduzindo, assim, a enorme quantidade de demandas judiciais.

\footnotetext{
"A efetiva participação democrática em saúde exige a movimentação das engrenagens da ordem jurídico-políticas, no intuito de favorecer sua progressiva realização, aumentar crescentemente as ocasiões nas quais o povo possa externar sua posição, colaborar para a resolução dos conflitos, assim garantindo-lhes concreta voz e vez" (MAGGIO, Marcelo Paulo. Saúde pública e sua tutela pelo Ministério Público. Curitiba: Juruá, 2018. p. 71).
} 
Partindo desse contexto, adota-se a existência de três espécies diferentes de resolução de conflitos, quais sejam: $a$ ) as resoluções estatais ou heterocompositivas dos conflitos (decisões judiciais); $b$ ) as resoluções estatais negociadas com as partes ou autocomposição, que podem se dar previamente ao início do processo, no âmbito jurisdicional, nos Cejuscs - Centros Judiciários de Solução de Conflitos e Cidadania - ou no âmbito de órgão auxiliar da Justiça, como a Defensoria Pública, o Ministério Público e a Advocacia Geral da União, e c) a resolução dos conflitos ou autocomposição dos conflitos, no âmbito extrajudicial, privado ou não.

A Professora Ada Pellegrini Grinover (2011) dispõe que, no âmbito dos métodos consensuais de solução de conflitos, agora com destaque na legislação brasileira, o instituto da mediação pode se apresentar como uma possibilidade eficaz ao abundante número de lides enfrentado diariamente pelos tribunais. E entre os estudiosos e juristas é de comum acordo a necessidade do acolhimento de um novo método e uma nova cultura no campo do SUS, sendo sugerida a mediação do direito à saúde (ou sanitária) como uma maneira de se empregar essa nova possibilidade acerca das demandas de saúde.

Sobre o tema da mediação sanitária, Delduque e Castro (2015, p. 30) esclarecem que:

A Mediação Sanitária é um modelo alternativo de resolução de conflitos na área da saúde. As relações de saúde transcendem a ótica bilateral do médico com o paciente, para envolver muitos outros atores presentes em um sistema de saúde, advindo, daí, conflitos de toda a ordem, internos e externos ao sistema, criando condições para a judicialização. Conflitos internos (como os assistenciais, organizativos e conflitos entre profissionais) geram desgastes e judicialização, como também fazem os conflitos gerados fora do sistema, mas com reflexos diretos dentro dele, assim como os conflitos sociais e conflitos legais igualmente geram a judicialização.

Enfatiza Assis (2013) que a mediação sanitária traz privilégios extensos no tocante aos procedimentos de prestação de serviços de saúde, pois proporciona o diálogo entre os indivíduos implicados e antepõe a construção de soluções que tendem à satisfação do direito não de uma maneira independente, mas conjuntamente com a procura pela melhoria do sistema como um todo.

A relação mais próxima que se institui entre os envolvidos ao participarem da mediação faz com que se obtenha a redução e prevenção de litígios, e isso ocorre graças à conexão que se forma entre todos os envolvidos, médicos, gestores e usuários.

À vista disso, a mediação sanitária consiste em facilitar o acordo entre as partes, tendo em vista que o SUS vem ganhando um importante auxílio para a resolução de conflitos com a iniciativa dos membros do Ministério Público, dos juízes, defensores públicos, advogados da União e procuradores que, estabelecendo grupos de mediação, concretizam um trabalho a partir do litígio individual, mediando o conflito entre o paciente e o gestor da saúde com o objetivo de impedir a ação judicial, buscando uma tutela eficiente traduzida por uma solução obtida de forma ampla, plena, rápida, útil, eficaz e econômica.

Nas palavras de Spengler (2017):

A mediação é a melhor fórmula até agora encontrada para superar o imaginário do normativismo jurídico, esfumando a busca pela segurança, previsibilidade e certezas jurídicas para cumprir com objetivos inerentes à autonomia, à cidadania, à democracia e aos direitos humanos. Portanto, as práticas sociais de mediação configuram-se em um ins- 
trumento de exercício da cidadania, na medida em que educam, facilitam e ajudam a produzir diferenças e a realizar tomada de decisões, sem a intervenção de terceiros que decidem pelos afetados em um conflito.

Neste viés de reduzir a judicialização e alcançar os direitos da população de forma cada vez mais célere e eficaz, tipificando e suprindo falhas no sistema, a mediação sanitária já vem sendo executada e tem mostrado efeitos satisfatórios em numerosos Estados da Federação.

Desse modo, a mediação sanitária vem sendo a melhor alternativa para combater esses impasses que o poder Judiciário sofre pelo grande número de processos. Esse instrumento pode efetivamente contribuir para a realização do direito à saúde, haja vista que cria espaços de debate extrajudicial. Nesse contexto, Gabriel Schulman e Alexandre Barbosa da Silva (2017) observam que, para a mediação administrativa, "deve-se ter em mente a possibilidade de espaços administrativos que avaliem especificamente os casos concretos dos pacientes e possam aferir a necessidade (ou não) de se liberar tratamentos para além dos protocolos clínicos".

Maria Célia Delduque e Eduardo Vazquez Castro (2015) citam dois exemplos acerca da utilização da mediação na área da saúde no Brasil:

(...) ocorrem no Ministério Público de Minas Gerais e na Defensoria Pública do Distrito Federal. Em Brasília, a Câmara Permanente Distrital de Mediação em Saúde, da Defensoria Pública do DF, tem por objetivo mediar conflitos entre os pacientes usuários do SUS-DF e os gestores da rede pública de saúde da Capital. No Estado de Minas Gerais, o Centro de Apoio Operacional das Promotorias de Justiça de Defesa da Saúde percorre regiões do Estado realizando reuniões de conciliação entre usuários e gestores, além de tratar de temas específicos, como saúde prisional, incorporação tecnológica e outros (DELDUQUE; CASTRO, 2015).

Delduque e Castro (2015) ressaltam que, em fevereiro de 2013, por meio de portaria conjunta entre a Secretaria de Saúde e a Defensoria Pública, foi criada uma Câmara (Camedis) especializada em questões de saúde com a finalidade de mediar divergências entre pacientes e os gestores da rede pública de saúde - um significativo avanço institucional na área.

Com a Camedis, ao invés de a Defensoria Pública ingressar judicialmente com os litígios de saúde, passou a procurar medidas extrajudiciais para esses conflitos por meio da prática da mediação. A atividade da Camedis, portanto, busca formalizar um pacto em favor do interessado (BRASIL, 2018).

Nesse cenário, Assis (2013) afirma que a mediação sanitária é uma concepção institucional empregada pelo Ministério Público "que visa discutir os desafios (problemas-causas) coletivos de saúde, no âmbito micro ou macrorregional, a partir do seu ativismo em uma agenda que possa envolver todos os atores do sistema, jurídicos ou não".

$E$, nesse sentido, o autor cita que a idealização da mediação sanitária parte da compreensão de duas circunstâncias político-institucionais: a necessidade da reorganização das ações e serviços de saúde, no âmbito regional, de forma solidária e não solitária, com participação democrática, visando à elaboração desse mesmo planejamento de saúde numa perspectiva integrada e regional; e o impacto negativo da judicialização da saúde no orçamento e no planejamento coletivo da saúde. 
É precisamente esse o preceito usado por Carlini ao ressaltar que o uso da mediação permite adentrar no contexto do outro para, pronunciado com os adequados motivos, desconstruir a demanda e estabelecer soluções mais adequadas para o conflito. De acordo com a autora, a mediação

restaura a importância do diálogo na vida social e minimiza a judicialização dos conflitos como caminho mais democrático para acesso à justiça. Isso só pode ser feito com eficiência se as razões do conflito puderem ser analisadas como caminho da compreensão, ou seja, se se compreender o outro, porque só essa forma é melhor para todos. A mediação, nessa dimensão, é a busca de um acordo que permita às partes em conflito lançar para o problema um outro olhar, de maior amplitude, porque diferente daquele que cada uma delas contemplava sozinha (CARLINI 2014).

E a maior parte das ações judiciais propostas com este desígnio é amparada pela Defensoria Pública Estadual em favor do cidadão interessado, tendo como réus o Estado federado e os municípios. E o Ministério Público, quando não age como substituto processual, o faz como fiscal da ordem jurídica.

É possível concluir que existe no Brasil a possibilidade do uso de meios de desjudicialização da saúde, como a conciliação e a mediação do direito à saúde, que são feitas por órgãos especializados ou mediadores escolhidos pelas partes, e a negociação direta, os quais são formas alternativas que estão previstos normativamente.

Para Delduque e Castro (2015) a adesão a meios alternativos de solução de conflitos, notadamente a mediação, procura obter "uma lenta transformação da sociedade brasileira, no sentido de criar a cultura do consenso e da cooperação na composição das disputas, aceitando-se um polissêmico conceito de justiça".

Nota-se, assim, que instrumentos para desjudicialização da saúde como a mediação sanitária, diálogo interinstitucional e a integral atuação dos indivíduos nas tomadas de decisão são opções capazes para a concretização do direito à saúde.

Assim, percebe-se que a desjudicialização concebe inúmeras probabilidades de desafogamento do poder Judiciário diante do aumento da litigiosidade das relações sociais, em um contexto que permanece cada vez mais complexo.

Como é urgente transformar a mediação sanitária em verdadeira e bem estruturada política pública, as Câmaras de Resolução de Litígios de Saúde (CRLS) ganham importância significativa por serem o locus propício para a concretização daquele método alternativo de solução de conflitos. Como lembra a doutrina, as CRLS são constituídas por

representantes das instituições essenciais à justiça, das Administrações Públicas federal, distrital, estaduais e municipais e das agências reguladoras da área, notadamente a Agência Nacional de Saúde e a Agência Nacional de Vigilância Sanitária, a fim de exercer verdadeira jurisdição administrativa, entabulando, em abstrato e com efeito vinculante para todos os entes federativos, entendimentos a respeito da saúde pública, uniformizando decisões aplicáveis aos casos concretos que porventura surgirem (ALÔ, 2016).

Desse modo, mostra-se a busca da uniformização das resoluções e das concepções sobre indagações a respeito da saúde. $O$ imprescindível acréscimo desse órgão seria o de uniformizar o entendimento a respeito do SUS para toda administração pública, pois dessa manei- 
ra as decisões administrativas que favorecessem um indivíduo seriam estendidas para todos aqueles que se encontrem na mesma condição, obstruindo a fragmentação do SUS por meio de processos individuais.

As Câmaras de Resolução de Litígios de Saúde (CRLS) são responsáveis por fazer o direcionamento administrativo, recolocar o indivíduo no fluxo do SUS e, além disso, possibilitar que sua base de dados seja utilizada como mais um dispositivo para a reorganização e avanço dos serviços de saúde. Refere-se, dessa maneira, a um dispositivo no qual todos os envolvidos são favorecidos e o cidadão recebe o serviço de saúde que precisa, sem a necessidade de recorrer ao poder Judiciário.

Desta forma, manifesta-se a procura da uniformização das resoluções e dos entendimentos acerca de questões relacionadas à saúde. O relevante aumento desse órgão seria o de uniformizar a percepção a respeito do SUS para toda a administração pública, uma vez que as decisões administrativas que favorecem o indivíduo serão estendidas para todos que se encontrem na mesma situação.

Aliás, no campo das CRLS e à luz da necessidade de se facilitar a comunicação entre os envolvidos, eis que fator imprescindível para a diminuição da judicialização, é importante trazer à tona a teoria dos diálogos institucionais. Isso porque a Câmara se põe como uma possibilidade de diálogo entre as inúmeras instituições envolvidas na tutela do direito à saúde, permitindo a concepção de uma decisão simultânea pelos indivíduos.

As CRLSs retratam um grande avanço institucional na seara da saúde e englobam integrantes da Defensoria Pública do Estado e da Defensoria Pública da União, assim como equipes de apoio técnico das Secretarias Municipal e Estadual de Saúde. Os integrantes das Defensorias operam no controle dos serviços a serem prestados, na utilização de medidas extrajudiciais e judiciais, na assistência dos casos e na concepção de sugestões de demandas na área das políticas públicas em saúde, e os representantes das Secretarias de Saúde concretizam o atendimento humanizado e exercem sufrágio técnico.

Alô (2016) ressalta que o principal acréscimo que tais órgãos trazem para o Sistema Único de Saúde seria uma

jurisdição administrativa com real visão de direito público, tendente a uniformizar entendimentos para toda Administração Pública, independente da esfera de governo, e para todos administrados, aliando a discricionariedade técnica de setores da área médica com o arcabouço jurídico, sendo certo que seus membros devem, necessariamente, ser dotados de garantias e prerrogativas, que lhes permitam exercer sua função com independência, como já abordado em tópico anterior. As decisões administrativas favoráveis aos pacientes seriam estendidas a todos os que se encontrassem na mesma situação fática, impedindo a fragmentação da universalidade do Sistema Único de Saúde por meio de demandas individuais.

Vislumbra-se, portanto, que as Câmaras têm significativo desempenho na uniformização das prestações administrativas, instituindo métodos comuns para todos os entes federativos. Torna-se cada vez mais urgente ter uma instância administrativa que, diante de um possível litígio, preze pela efetiva e satisfatória comunicação entre as partes envolvidas.

Além da aproximação entre os componentes do sistema, a existência de diálogos interinstitucionais entre os poderes constituídos, Ministério Público e Defensoria Pública pode 
facilitar a realização de parcerias e convênios, o estabelecimento de procedimentos padronizados de entrega de medicamentos, por exemplo, e ajudar o poder Judiciário a compreender e ter uma dimensão melhor do fluxo dos recursos públicos disponíveis.

Nesse sentido, o Tribunal de Justiça do Estado do Paraná, por meio de sua 2a Vice-Presidência, tem incentivado a criação de Cejuscs temáticos, como o Cejusc da Família, Bancário, Fazendário, Criminal, Cível, da Saúde, do Procon e o da Defensoria Pública, focando seus esforços nos meios pré-processuais de solução de conflitos. Todos os acordos celebrados pela Defensoria Pública, antes do ajuizamento da ação, são encaminhados diretamente ao juiz coordenador do Cejusc local, para imediata homologação, passando a ter status de título executivo judicial.

Além disso, no Paraná, há intenso diálogo entre o poder Judiciário, Ministério Público, Defensoria Pública, Procuradoria-Geral do Estado e Secretaria Estadual de Saúde para a utilização dos Cejuscs. Um exemplo atual são as tratativas para o fornecimento de medicamentos e tratamentos pelo sistema público de saúde, mas que ainda não estão ao alcance de toda a população. Um deles é o medicamento Bevacizumab, indicado para tratamentos oncológicos. Este medicamento é produzido e fornecido em grande número de doses. O cumprimento das decisões em ações individuais, além de onerosas ao Estado, proporcionam grandes desperdícios. Vislumbra-se que, concentrando as demandas, mesmo que em procedimentos individuais pré-processuais nos Cejuscs, pode-se autorizar o fornecimento em audiências de conciliação pré-processual, concentrando as aplicações do remédio em datas que otimizarão tanto a mão de obra do profissional que realiza a aplicação, como também as quantidades de doses que deixarão de ser desperdiçadas. Com isso, evita-se futuro questionamento judicial da concessão individual de medicamento não disponibilizado pelo SUS, mas devidamente registrado na Anvisa.

\section{PRIORIDADE PARA AS AÇÕES COLETIVAS}

Nesse contexto, um instrumento digno de destaque, e que também abrange a desjudicialização, é a coletivização das demandas judiciais, isto é, a coletivização de demandas individuais. De acordo com Alô (2016):

Em um olhar superficial, pode parecer contraditório suscitar a desjudicialização das demandas de saúde por meio da judicialização de novas demandas. Ocorre que, ao defendermos o tratamento do direito à saúde de maneira transindividual, ou seja, com o manejo de ações coletivas, busca-se justamente a configuração de decisões erga omnes, nos termos do art. 103, inc. I, da Lei n. 8.078/90, promovendo, assim, a molecularização de demandas. Evita-se, portanto, a proliferação de demandas individuais com pretensões idênticas, impondo o Estado-juiz decisão isonômica para todos os usuários do Sistema Único de Saúde, a qual deve, inclusive, ser internalizada na estrutura da Administração Pública brasileira, por meio de atos normativos infralegais.

Os impactos sociais e financeiros ocasionados pelas sentenças em favor de um só indivíduo podem incidir em detrimento do coletivo. Neste caso, pode-se citar o princípio da equidade, que impõe uma distribuição mais igualitária por meio de políticas públicas e não, simplesmente, a solução de cada caso concreto. 
Segundo a processualista Ada Pellegrini Grinover, o modo mais eficaz de lidar com políticas públicas é por intermédio de ações coletivas. Ela ainda defende que as ações individuais envolvendo o fornecimento do mesmo medicamento sejam coletivizadas, estabelecendo-se um diálogo entre os componentes dos poderes Executivo e Judiciário. $\mathrm{O}$ desígnio é poder empregar a decisão de maneira universal e igualitária (GRINOVER, 2011).

Sobre as ações coletivas, Kazuo Watanabe (2011), afirma:

O legislador claramente percebeu que, na solução dos conflitos que nascem das relações geradas pela economia de massa, quando essencialmente de natureza coletiva, o processo deve operar também como instrumento de mediação dos conflitos sociais neles envolvidas, e não apenas como instrumento de solução de lides. A estratégia tradicional de tratamento das disputas tem sido de fragmentar os conflitos de configuração essencialmente coletiva em demandas-átomo. Já a solução dos conflitos na dimensão molecular, como demandas coletivas, além de permitir o acesso mais fácil à Justiça, pelo seu barateamento e quebra de barreiras socioculturais, evitará a sua banalização que decorre de sua fragmentação e conferirá peso político mais adequado às ações destinadas à solução desses conflitos coletivos. (...). Tome-se o exemplo da ação aforada para o "desbloqueio de cruzados". Se a inconstitucionalidade do bloqueio é arguida incidenter tantum, como mera questão prejudicial para justificar o pedido de desconsideração dos bloqueios individualizados, estamos diante de demanda individual, quando muito com pluralidade de partes. Para que a ação seja verdadeiramente uma demanda coletiva, o autor deverá, mediante enunciação de causa de pedir adequada (v.g. inconstitucionalidade), postular a desconstituição do ato geral de bloqueio de cruzados, postulando provimento jurisdicional que beneficie de modo uniforme todas as pessoas que se encontrem na mesma situação.

Ada Pellegrini Grinover (2011) ainda pontua que as ações individuais no campo da saúde devem ser utilizadas apenas para demandas que se relacionam com o mínimo existencial, com o restante dos litígios devendo ser coletivizado.

Segundo Suzana Henriques da Costa (2011), o mínimo existencial é o limite daquilo que pode ser conferido individualmente, a fim de que o indivíduo tenha condições de se desenvolver plenamente na vida em sociedade. Também resguarda a possibilidade de debater política pública em ação individual, desde que se trate do mínimo existencial.

Para Zygmunt Bauman (2001) a individualização é a usura e a lenta desagregação da cidadania:

Se o indivíduo é o pior inimigo do cidadão, e se a individualização anuncia problemas para a cidadania e para a política fundada na cidadania, é porque os cuidados e preocupações dos indivíduos enquanto indivíduos enchem o espaço público até o topo, afirmando-se como seus únicos ocupantes legítimos e expulsando tudo mais do discurso público.

A individualização das demandas, no entanto, é uma das causadoras da crise com que se depara o poder Judiciário, pois contribui com a quantidade de litígios e com a demorada solução das lides. Salientam Mauro Cappelletti e Bryant Garth (1998):

Em muitos países, as partes que buscam uma solução judicial precisam esperar dois ou três anos, ou mais, por uma decisão exequível. Os efeitos dessa delonga, especialmente se considerados os índices de inflação, podem ser devastadores. Ela aumenta os custos para as partes e pressiona os economicamente fracos a abandonar suas causas, ou a acei- 
tar acordos por valores muito inferiores àqueles a que teriam direito. A Convenção Européia para Proteção dos Direitos Humanos e Liberdades Fundamentais reconhece explicitamente, no artigo 6으, parágrafo 10 que a Justiça que não cumpre suas funções dentro de "um prazo razoável" é, para muitas pessoas, uma Justiça inacessível.

Assim sendo, a individualização pode constituir em atraso processual e destituir dos cidadãos o seu tempo, algo significativo na época atual nomeada por Zygmunt Bauman como a "modernidade líquida". Nessa perspectiva, a individualização atinge a população e prejudica o acesso à Justiça, direito essencial.

Antônio Carlos Marcato (2001) afirma que foi feita uma sugestão a respeito de uma razoável redução do custo do processo e também da sua duração por meio de uma técnica de coletivização de demandas individuais. A ideia fundamental é que determinadas demandas individuais envolvessem interesses basicamente homogêneos e que, assim, elas pudessem ser fundidas em um processo apenas, o qual traria ao final uma solução que atenderia a todos os litigantes.

Assim sendo, uma das notáveis soluções para mitigar o fenômeno da judicialização pode ser detectada na molecularização dos conflitos, ou seja, no aproveitamento da tutela coletiva como meio mais adequado e célere de pacificação social. O desígnio de instrumentos processuais não adequados pode ocasionar decisões judiciais incongruentes com a realidade da sociedade.

\section{O DEBATE DA POLÍTICA PÚBLICA DE SAÚDE POR MEIO DE AUDIÊNCIAS PÚBLICAS}

Outro tema significativo a ser examinado, na acepção de fortalecer a base administrativa da resolução de conflitos na área da saúde, centra-se nos representantes eleitos para debater a política pública de saúde com a sociedade civil em audiências públicas.

As audiências públicas fomentam a democracia participativa, possibilitando o debate público sobre determinado assunto, admitindo que a sociedade espontaneamente envolvida tenha direito à voz. Nessas ocasiões as autoridades públicas examinam a sociedade civil na procura por elementos e soluções de conflitos alternativos. A sociedade civil apresenta o ensejo de expressar suas inquietações aos órgãos de saúde pública e de tal modo obter esclarecimentos e probabilidades dos representantes do poder público, instituindo uma conversação de maneira franca. Deste modo, a audiência pública é coerente com a visão democrática de Estado, em que a fala da população precisa ser analisada quando da tomada de deliberações.

Nesta acepção, a audiência pública foi uma prática significativa para o debate democrático sobre direito à saúde, caracterizada pelo comparecimento de profissionais da área médica, gestores públicos, juristas, professores e usuários do SUS. O debate na audiência pública, contudo, concentra-se no que Nancy Fraser (1989)' chama de procedimentos jurídicos, administrativos e terapêuticos, o que causa uma análise limitada de demandas políticas sob esses três prismas.

De acordo com os conceitos clássicos de Giddens (1991), pode-se expor que as audiências públicas trariam segurança para a sociedade, não somente no sistema de saúde pública, como também no respectivo sistema do Direito. Consoante com os técnicos do programa e todos os 
estudos referentes ao SUS, utilizando-se dos métodos adequados de solução de conflitos, como é o caso da mediação na área da saúde, entre outros, foram apresentados efeitos positivos.

Nesse mesmo âmbito, a desjudicialização da saúde também é fomentada quando do uso do Núcleo de Apoio Técnico (NAT) dos tribunais ou do CNJ antes da ação judicial; pela plena adaptação do pleito; quando da verificação de que o custo do tratamento é baixo e de que sua efetividade já está exposta; quando da constatação de que o medicamento está na Relação Nacional de Medicamentos Essenciais (Rename), visto que a concessão é imperativa; e quando da avaliação da possibilidade terapêutica para o tratamento do paciente.

A desjudicialização provoca uma extensa atuação da população em debates públicos de concretização do direito à saúde. Essa atuação é na maioria das vezes estimulada por meio de audiências públicas e inserção nos Conselhos.

Em dezembro de 2017, por exemplo, o Supremo Tribunal Federal realizou audiência pública com o tema "Justiça e Saúde", que contou com a participação de 32 entidades e personalidades. É admissível, portanto, ressalvar que a desjudicialização possibilitará o debate da população em assuntos políticos, tornando-se, assim, acessível para todos os indivíduos a interpretação constitucional e admitindo a melhor abordagem da demanda, na medida em que é um contraponto à judicialização ao antepor medidas alternativas e diálogos para litígios que abranjam políticas públicas de saúde (RINGEISEN, 2016).

\section{CONCLUSÃO}

Neste artigo foram apresentadas alternativas à judicialização no âmbito do direito à saúde, deduzindo-se que a desjudicialização em meio à crise do poder Judiciário se manifesta como uma alternativa admissível e acessível para possibilitar à população brasileira um digno acesso à Justiça e de certa forma uma Justiça mais célere e efetiva, pois contribui com o desafogamento do poder Judiciário.

Primeiramente foi analisada a mediação sanitária, a qual consiste em um importante instrumento voltado a proporcionar uma cultura baseada no acordo entre os indivíduos, com custos e prazos mais baixos, além da assistência nas relações antes conflituosas.

Foi abordada também a expansão e a instalação das Câmaras de Resolução de Litígios de Saúde (CRLS), as quais são aptas para impedir conflitos conexos à tutela do direito à saúde, sem intervenção judicial, mas de forma célere e efetiva, sendo de grande importância observar que essa ação traz a pertinência da teoria dos diálogos institucionais.

Além disso, tratou-se também do incentivo do poder Judiciário, por meio de audiências pré-processuais nos Cejuscs, à utilização de meios socialmente adequados de solução de conflitos e que contribuem para a resolução do conflito no seu nascedouro. Resolve-se o conflito, impedindo o surgimento da lide.

Posteriormente foi apontada a necessidade de se dar prioridade para as ações coletivas, observando-se que, dentro da ideia de tutela coletiva, discute-se a relevância da discussão da política pública de maneira molecularizada.

Enfrentou-se, também, a questão do debate da política pública de saúde por meio de audiências públicas como uma função institucional, em que se concretiza a democracia participativa e se permite o debate público sobre determinado assunto. 
Conclui-se, portanto, que os meios socialmente adequados para resolução de conflitos proporcionam aos cidadãos um efetivo acesso à Justiça e em menor tempo, desjudicializando-se conflitos de interesse. Tais instrumentos permitem a redução de conflitos relativos ao direito à saúde, sem intervenção judicial, tendo assim um progresso no que respeita à celeridade e à efetividade das demandas.

\section{REFERÊNCIAS}

ALÔ, Bernard dos Reis. Desjudicializando o direito à saúde - o papel da Defensoria Pública nesse processo. Revista CEJ, Brasília, a. XX, n. 70, p. 101-112, set./dez. 2016. (Orientação Ricardo Perlingeiro).

ANDREUCCI, Álvaro Gonçalves Antunes; LOUBACK, Cristian Lima dos Santos. A desjudicialização pelos cartórios extrajudiciais e o acesso à justiça na modernidade líquida. Interesse Público - IP, Belo Horizonte, a. 20, n. 112, p. 55-71, nov./dez. 2018.

ASSIS, Gilmar de. Medição sanitária. Cad. Iber. Amer. Direito. Sanit., Brasília, v. 2, n. 2, jul./dez. 2013. CONGRESSO IBEROAMERICANO DE DIREITO SANITÁRIO, 3., CONGRESSO BRASILEIRO DE DIREITO SANITÁRIO, 2., 2013. Anais [...]. Disponível em: http://www.cadernos.prodisa.fiocruz.br/index.php/cadernos/article/download/98/140. Acesso em: 30 ago. 2019.

BAUMAN, Zygmunt. Modernidade líquida. Rio de Janeiro: Zahar, 2001.

BRASIL. Conselho Nacional de Justiça. Justiça em Números 2018: ano-base 2017. Brasília: CNJ, 2018. Disponível em: http://www.cnj.jus.br/programas-e-acoes/pj-justica-em-numeros. Acesso em: 2 set. 2019.

CAPPELLETTI, Mauro; GARTH, Bryant. Acesso à Justiça. Porto Alegre: Fabris, 1988.

CARLINI, Angélica. Judicialização da saúde pública e privada. Porto Alegre: Livraria do Advogado Editora, 2014.

COSTA, Suzana Henriques da. O Poder Judiciário o controle de políticas públicas: uma breve análise de alguns precedentes do Supremo Tribunal Federal. In: GRINOVER, Ada Pellegrini; WATANABE, Kazuo (org.). O controle jurisdicional de políticas públicas. Rio de Janeiro: Forense, 2011. p. 451-466.

DELDUQUE, M. C.; ALVES, S. M.; DALLARI, S. G. Decreto que institui a Política Nacional de Participação Social: impactos na saúde. Cadernos de Saúde Pública, Rio de Janeiro, v. 30, n. 9, p. 30, 2015.

DELDUQUE, Maria Célia; CASTRO, Eduardo Vazquez. A mediação sanitária como alternativa viável à judicialização das políticas de saúde no Brasil. Saúde Debate, Rio de Janeiro, v. 39, n. 105, p. 506-513, abr./jun. 2015. Disponível em: http://www.scielo.br/pdf/sdeb/v39n105/0103-1104-sdeb-39-105-00506. DOI: http://dx.doi. org/10.1590/0103-110420151050002017. Acesso em: 2 set. 2019.

FELTEN, Márcia Silvana. O exaurimento do modelo jurisdicional: ponderações sobre um diagnóstico possível. In: SPENGLER, Fabiana Marion; COPELLI, Giancarlo Montagner; JAQUES, Marcelo Dias (org.). O sistema de justiça e suas instituições: ensaios à luz dos direitos humanos e democracia. Santa Cruz do Sul: Essere Nel Mondo, 2014.

FRASER, N. Unruly practices: power, discourse, and gender in contemporary social theory. Minneapolis: University of Minnesota Press, 1989.

GIDDENS, Anthony. As consequências da modernidade. Tradução Raul Fiker. São Paulo: Unesp, 1991.

GRINOVER, Ada Pellegrini. O controle jurisdicional de políticas públicas. In: GRINOVER, Ada Pellegrini; WATANA$\mathrm{BE}$, Kazuo (coord.). O controle jurisdicional de políticas públicas. Rio de Janeiro: Forense, 2011.

KLEIN, Vinicius. Teorema de Coase. O que é análise econômica do direito: uma introdução. Coord. Marcia Carla Pereira Ribeiro e Vinicius Klein. Belo Horizonte: Editora Fórum, 2011.

KRUGMAN, Paul; WELLS, Robin. Introdução à economia. Tradução Helga Hoffman. 3. ed. São Paulo: Elsevier, 2015.

MAGGIO, Marcelo Paulo. Saúde pública e sua tutela pelo Ministério Público. Curitiba: Juruá, 2018.

MARCATO, Antonio Carlos. O processo monitório brasileiro. 2. ed. São Paulo: Malheiros Editores, 2001.

RINGEISEN, Adriana Torquato da Silva. Mediação de conflito no Sistema Único de Saúde: visões e práticas de um a experiência no município de Natal/RN. 2016. 119f. Dissertação (Mestrado em Saúde Coletiva) - Universidade Federal do Rio Grande do Norte, Centro de Ciências da Saúde, Natal, RN, 2016.

SCHULMAN, Gabriel; SILVA, Alexandre Barbosa. (Des)judicialização da saúde: mediação e diálogos interinstitucionais. Revista Bioética, v. 25, n. 2, 2017.

SCOCUGLIA, Livia. Política pública deve ser discutida em ação coletiva. Consultor Jurídico - Conjur, 2013. Disponível em: https://www.conjur.com.br/2013-set-04/politica-publica-discutida-acao-coletiva-ada-grinover. Acesso em: 3 set. 2019. 
SICA, Heitor Vitor Mendonça. Evolução legislativa da fase de saneamento e organização do processo. Revista de Processo, São Paulo: Revista dos Tribunais, v. 255, p. 435-460, 2016.

SILVA, Alexandre Barbosa da. A intervenção do judiciário nas políticas públicas de saúde: elementos de (não) justificação constitucional. In: MEZZAROBA, O. et al. (org.). Direitos sociais e políticas públicas l. Curitiba: Clássica, v. 25, p. 465-494, 2014.

SPENGLER, Fabiana Marion. Mediação de conflitos - da teoria à prática. 2. ed. Porto Alegre: Livraria do Advogado, 2017.

TOALDO, Adriane Medianeira; BERGHAHN, Márcia Muhlbaier. Desjudicialização do direito à saúde: a integração entre a sociedade e o estado como alternativa de enfrentamento. In: COSTA, Marli Marlene Moraes da; RODRIGUES, Hugo Thamir (org.). Direito \& Políticas Públicas IX. Curitiba: Multideia, 2014.

WATANABE, Kazuo. O controle jurisdicional de políticas públicas. In: GRINOVER, Ada Pellegrini; WATANABE, Kazuo (coord.). O controle jurisdicional de políticas públicas. Rio de Janeiro: Forense, 2011. 